\title{
Domestic wastewater treatment by vertical filter planted with Papyrus Cyperus: the plant adaptation in the new environment.
}

\author{
Mustapha El Hafidi ${ }^{1,2, *}$, Latifa Mouhir ${ }^{1}$, Mohamed Laaouan ${ }^{2}$, Amal Kabbour ${ }^{1}$, and Laila Saafadi ${ }^{1}$ \\ ${ }^{1}$ Faculty of Sciences and Techniques of Mohammedia, Hassan II University, Casablanca, Morocco \\ ${ }^{2}$ National Office of Electricity and Potable Water (ONEE), Rabat, Morocco
}

\begin{abstract}
The wastewater from rural areas or small agglomerations usually discharged in an unsuitable manner requires an appropriate treatment. The constructed wetland has revealed a great potential due to the good performance, reasonable investment and easier management. The aim of this article is to present the results of the adaptation period (45 days) of a substitute plant, Papyrus Cyperus, in the new environment. Investigations were carried out on a concrete vertical filter of 12 $\mathrm{m} 2$ filled with gravel available on the local market. Monitoring was provided mainly through two squares of $1 \mathrm{~m} 2$ each. The results were compared with a control square planted in natural soil. The filter and the control square were planted with a density of 3 plants / $\mathrm{m} 2$ and were fed by necessary water needs. At the completion of the adaptation phase, the density increased by 26 stems at each Square of the filter. The stems exceeded $1 \mathrm{~m}$ in height (Square 1: $110 \mathrm{~cm} \pm 0.9$, Square 2: $123.5 \mathrm{~cm}$ \pm 0.7 and control Square: $113 \mathrm{~cm} \pm 0.9$ ). The mean perimeter exceeded $5 \mathrm{~cm}$ at the filter (square 1: $5.6 \mathrm{~cm} \pm 0.5$ and square $2: 5.5 \mathrm{~cm} \pm 0.1)$ and almost $4 \mathrm{~cm}$ in the control square $(3.7 \mathrm{~cm} \pm 0,2)$. The shoots reached during the last half of the adaptation period 20 shoots in the Squares of the filter and 16 shoots in the control square. It should be noted that the young stems are adapted quickly than the older ones. Papyrus Cyperus plants have completed this phase with good health (absence of disease symptoms) and organ development similar to control plants.
\end{abstract}

\section{Introduction}

The wastewater from rural areas or small agglomerations usually discharged in an unsuitable manner requires an appropriate treatment. However, the issue of treatment techniques adapted to this context remains a singular point, especially with the financial deficit, non-staff qualification and the isolation of these communities.

The constructed wetland $(\mathrm{CW})$ has revealed a great potential due to the good performance, reasonable investment and easier management [1,2]. Dr. Käthe Seidel, in Germany, was the first to experiment CW in the 1960s [3]. In France, the experiment started in 1978 [3] and since 2008 , more than $60 \%$ of the new treatment plants between 50 and 2000 people equivalent (p.e.) are carried out on the principle of CW [4]. Phragmites Australis, the common reed [4,5], is the conventionally plant used in temperate zones [4].

In Morocco, the wastewater from rural areas is a topical issue. Facilities are rare in this areas (connection rate below $10 \%$ ) and are generally limited to latrines, septic tanks and soakaway made by population that do not exceed a depollution rate of 3\% (Interior Ministry of Morocco 2015).
As part of the search for solutions adapted to the Moroccan littoral context, a vertical flow constructed wetland (VFCW) was carried out at the training wastewater treatment plant (WWTP) of the National Office of Electricity and Drinking Water (ONEE) in Rabat. The VFCW was planted by a substitute plant (Papyrus Cyperus) and was filled with a material available on the local market.

The aim of this article is to present the results of the adaptation period of the plant Papyrus Cyperus in the new environment in order to avoid that the disturbances linked to the change of medium will attributed to the nominal operating phase.

\section{Material and Methods}

\subsection{Experimental device}

Investigations were carried out on a concrete vertical filter of $12 \mathrm{~m}^{2}$ (Fig.1). The filling material is a crushed and washed gravel bought on the local market. From the top to the bottom, different layers were:

- $15 \mathrm{~cm}$ of $2 / 4 \mathrm{~mm}$ gravel ; 
- $15 \mathrm{~cm}$ of $5 / 8 \mathrm{~mm}$ gravel as a transition layer;

- $15 \mathrm{~cm}$ of $13 / 20 \mathrm{~mm}$ gravel to drain the filter.

Papyrus Cyperus plants were bought at a local nursery. Plantation was carried out at the end of May 2018 with a density of three plants $/ \mathrm{m}^{2}$. Each plant was placed with its clod and some compost.

The choice of Papyrus Cyperus was based mainly on its morphological and intrinsic characteristics [2,6,7], which guarantee the desired mechanical action (Tab.1) as well as its availability on the local market and its perfect integration into the landscape (ornamental plant).

Table1: Summary of Papyrus Cyperus satisfaction to the properties of a VFCW plants [6]

\begin{tabular}{|l|c|}
\hline \multicolumn{1}{|c|}{ Property } & Papyrus Cyperus \\
\hline Water stress & $?$ \\
\hline Gravel support & $?$ \\
\hline Direct light & yes \\
\hline Perrenial / non-woody & yes \\
\hline Rapid development & $?$ \\
\hline Homogeneous development & $?$ \\
\hline rhizomatous & yes \\
\hline $\begin{array}{l}\text { Height }>\text { 1m, diam. stems 0,5 to } 2 \\
\text { cm }\end{array}$ & yes \\
\hline No water retention by aerial parts & yes \\
\hline non-toxic plant (sap, leaves ...) & yes \\
\hline unprotected species & yes \\
\hline Non Invasive species & yes \\
\hline
\end{tabular}

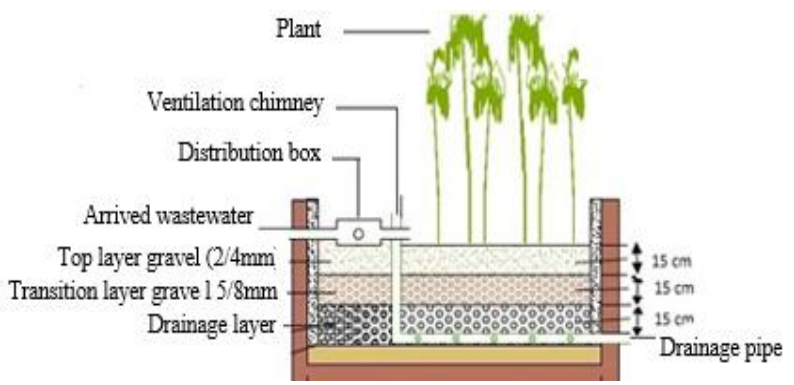

Figure 1: Cross section of the planted filter

\subsection{Monitoring protocol of adaptation period}

Before the operation under nominal conditions, the plants were monitored during an adaptation period (45 days). The objective is to test the plants adaptation to the new environment (the top layer gravel). To do this, two squares of $1 \mathrm{~m}^{2}$ were identified at the filter: the first square (S1) is located near the feed point and the second one (S2) at the filter outlet (Fig.2). The results were compared with a square control (SC) of a $1 \mathrm{~m}^{2}$ planted with the same density in the natural soil in a site bordering the vertical bed.

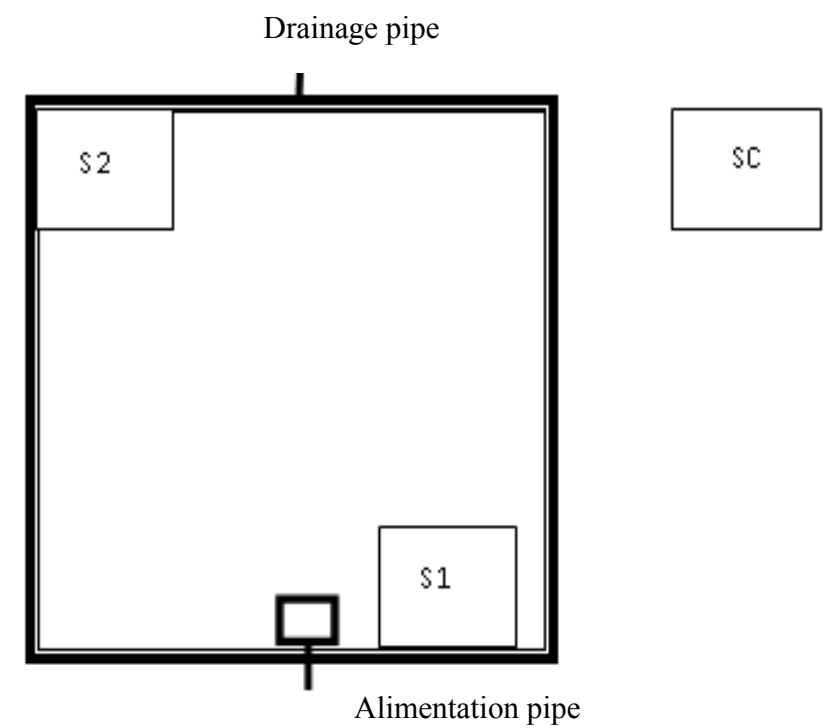

Figure 2: Squares situation in the filter

The observations and measurements were done every two weeks over the adaptation period. At each measurement campaign, a set of parameters [6] per organ per square were recorded:

Table 2: Monitoring parameters by organ during the adaptation period

\begin{tabular}{|l|l|}
\hline Organ & \multicolumn{1}{|c|}{ Parameter } \\
\hline \multirow{5}{*}{ Stem } & $\begin{array}{l}\text { - Density: number of stems per square; } \\
\text { - Maximum height: The average of three } \\
\text { high stems. The height is measured from the } \\
\text { ground to the plant apex; } \\
\text { - Perimeter: the average of three perimeters. } \\
\text { The perimeter is measured at the height of } \\
20 \text { cm from the ground; } \\
\text { - State of health: observation of the } \\
\text { symptoms (chlorosis, lodging, death etc.); } \\
\text { - Development according to age: monitoring } \\
\text { the height of the stems of different ages }\end{array}$ \\
\hline Leaf & $\begin{array}{l}\text { - State of health: observation of symptoms } \\
\text { (wilting, mottling, etc.). }\end{array}$ \\
\hline \multirow{2}{*}{ Shoot } & $\begin{array}{l}\text { - Appearance and growth. A shoot is } \\
\text { considered as a plant when its stem exceeds } \\
20 \mathrm{~cm} .\end{array}$ \\
\hline
\end{tabular}

Furthermore, at each campaign an overall follow-up for the filter was carried out through:

- the identification of the vegetative cycle;

- the plants health;

- the weeds and the pests presence;

- the maintenance activities.

During the adaptation period, the filter and the SC were fed with the necessary water needs. Feeding was done daily with tap water for the first week and then once every two days by treated water of the training WWTP. 


\subsection{Weather data}

No rainfall was observed during the adaptation period [8]. The temperature oscillated between 12 and $25^{\circ} \mathrm{C}$.

\section{Results and discussion}

The density in squares (Fig.3) increases very slowly during the first fortnight and does not exceed three stems in S2. It was not until the end of the first month to see the number doubled and tripled by the end of the adaptation period (33, 36 and 29 stems at S1, S2 and SC respectively).

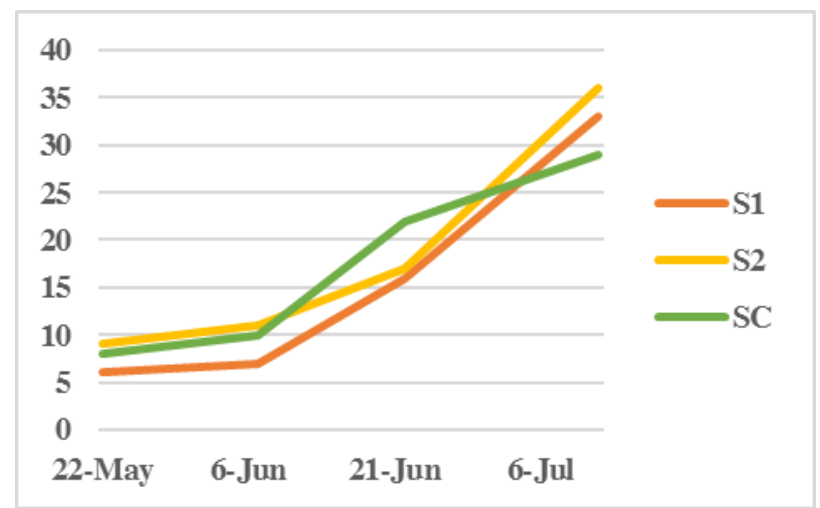

Figure 3: Plants density (number of stems/ square)

The stem maximum height followed a regular rhythm (Fig.4). Throughout the adaptation period, the maximum heights of stems increased by $25,37.5,18 \mathrm{~cm}$ at $\mathrm{S} 1, \mathrm{~S} 2$ and CS respectively.

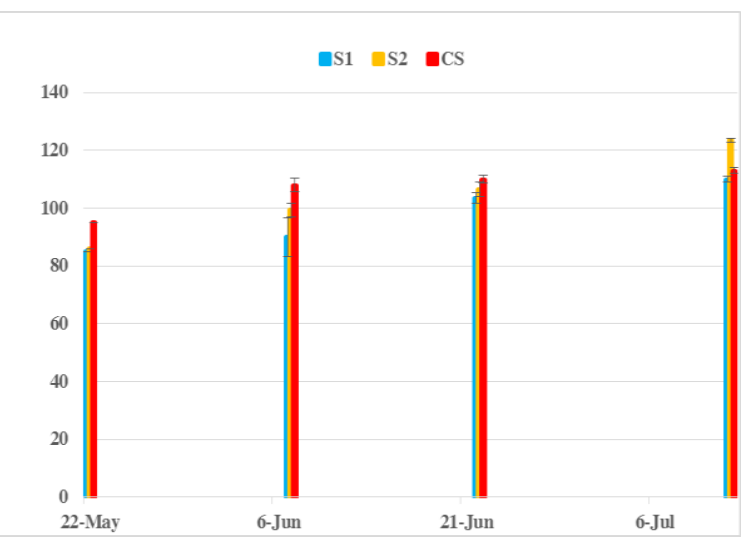

Figure 4: Stems maximum height per square $(\mathrm{cm})$

One important criteria of the plant selection is the stem diameter / perimeter. This criteria conditions the weed cutting (easy or difficult) and the plant mechanical action $[1,6]$. For the Papyrus Cyperus, the average perimeter of the stems in the three squares evolved in an accelerated speed (Fig.5). The perimeters go from 1.5, 1.6 and 1.7 $\mathrm{cm}$ to $5.6,5.5$ and $3.7 \mathrm{~cm}$ at the end of the adaptation period at S1, S2 and CS respectively. However, during the last two weeks of the period, the average perimeter in the CS was regressed; it went from $4 \mathrm{~cm}$ to $3.7 \mathrm{~cm}$. This regression could be explained by the presence of weeds.

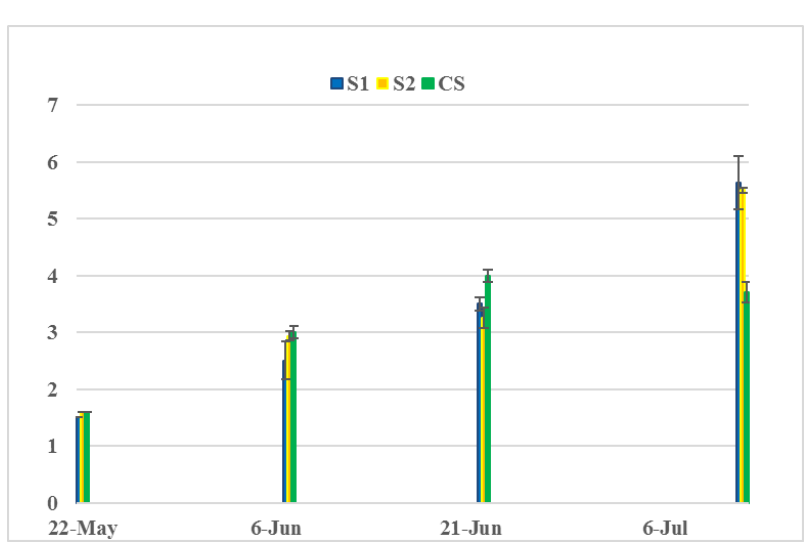

Figure 5: Stems perimeters per square $(\mathrm{cm})$

In order to monitor the plants health in the squares, the symptoms that appeared on the various organs of the plant were listed during the adaptation period (fig.6).

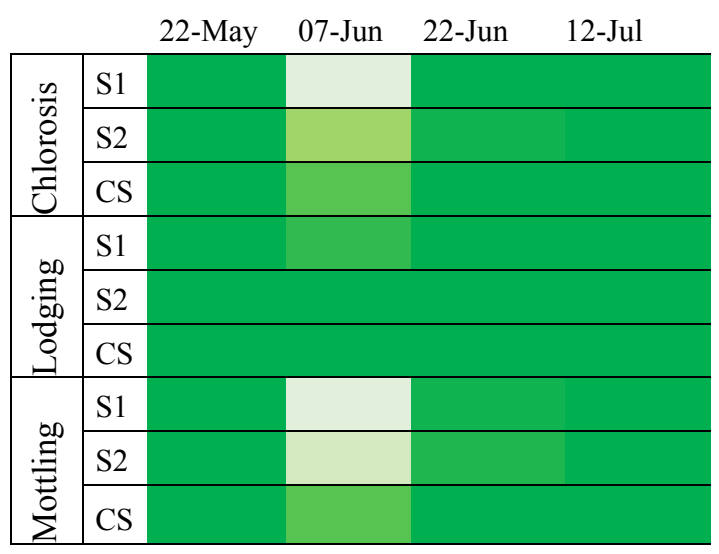

Full strength: more than $90 \%$ are not affected plants.

Between $35 \%$ et $65 \%$ are affected plants.

Critical condition: more than $65 \%$ are affected plants.

Figure 6: Observations synthesis of the plants health state per square

Observations on the organs color (stem and leaf) reflect the photosynthetic activity of the plant [6]. During the first fortnight, very negative consequences were observed on plants photosynthetic system at S1 and S2: accentuated chlorosis and mottling and even deaths (Fig.6 and 7). Thereafter, almost all plants returned to their green color. In the CS, slight damage of photosynthetic system occurred during the first week and then disappeared that permitted to the plants to return to normal state (Fig.6). 


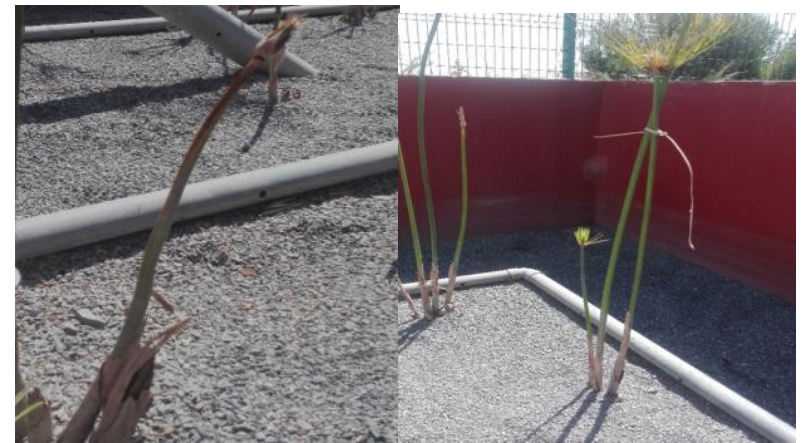

Figure 7: Photos taken during the second control (07 June): On the left a plant in S1 with dead leaves and an accentuated chlorosis. On the right, a plant in S2 with clear organs (chlorosis and mottling).

The osmotic potential consolidates all the data on leaf wilting, plant habit and its different degrees of vigor[6]. It represents the plant capacity to adjust its osmotic potential to changes in the environment (water stress and anoxic stress) in order to maintain the turgidity necessary for cell growth and avoid plasmolysis [6]. Because of the irrigation was done by the water requirements, the plants in filter bed and CS did not suffer to maintain the osmotic potential throughout the adaptation period (Fig. 6).

Vegetative propagation corresponds to observations made on shoot. This indicator provides information on the root system that can emit the new $[2,6]$.

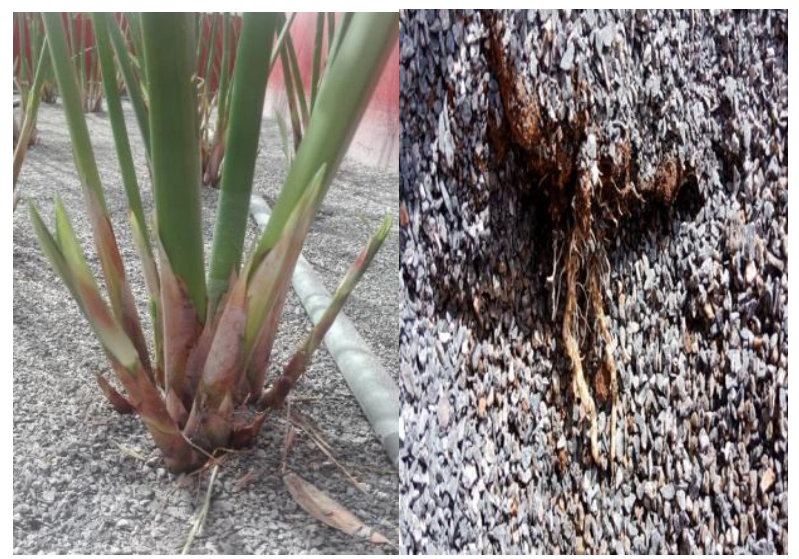

Figure 8: On the left, the shoots apparition at S1. On the right the root system of a plant at S1 on June 15 th.

The shoot number emitted two weeks after the start of the experiment was very limited: 4,1 and 6 at S1, S2 and CS respectively. Thereafter, apparitions accelerated to reach during the last fortnight 20 shoots at $\mathrm{S} 1$ and $\mathrm{S} 2$ and 16 shoots at CS. This means that the root zone of the plants was in development during this period (Fig.8 and 9).

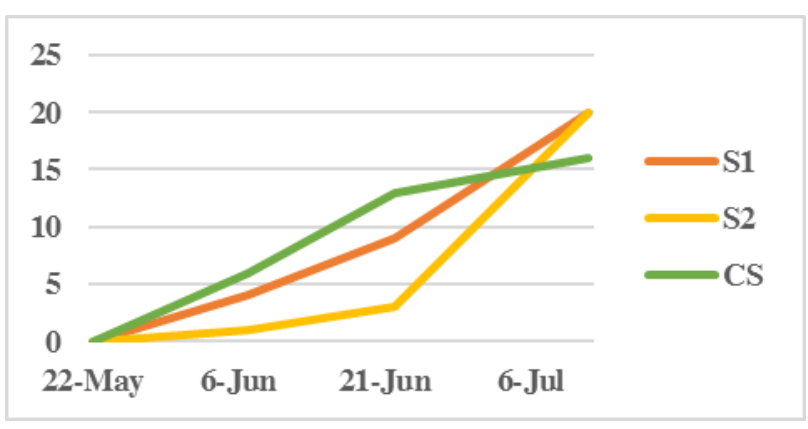

Figure 9: Shoots number per square

In addition, it could be seen that from the third week, the plants in S1 and S2 gained more height, perimeter and shoots than CS. This might be explained by the influence of the recurrent presence of weeds in the CS. Even at low levels, weeds competing with the CS plants could affect the rate of plant growth.

On the other hand, the follow up of the entire filter revealed the following information:

- Confirmation of results above regarding S1 and S2 for all the filter plants;

- Absence of competitive weeds and pests on the filter;

- Except some accidental actions, the filter did not require maintenance activities;

- Blooming began at the end of June like a normal cycle (Fig.10).

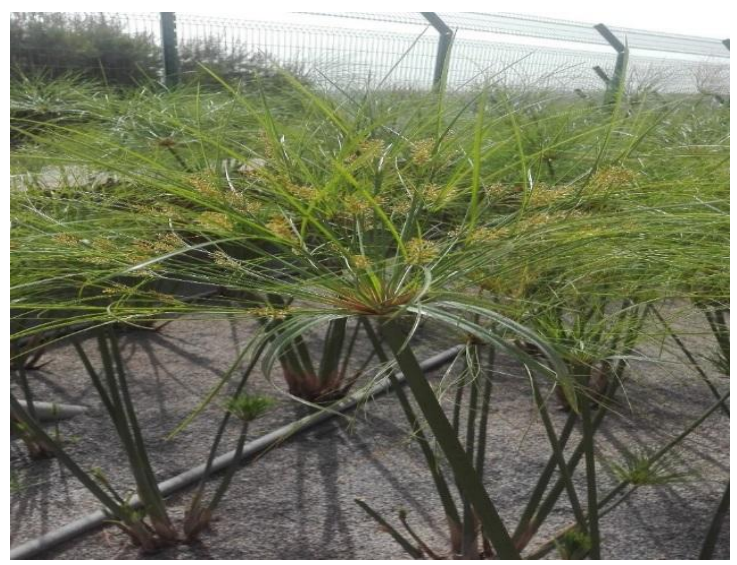

Figure 10: The beginning of blooming in the filter.

Plants in good health after a month

In order to test if the age could play a role in the adaptation at the new environment, we proceeded to the identification of three stems of different ages per square (Fig. 11, 12 and 13).

The stems initially planted (number 3 ) followed a slow development which did not exceed $25 \mathrm{~cm}$ during the adaptation period at the three squares. This evolution follows a slow pace that reaches $1 \mathrm{~cm}$ in the last fortnight of the adaptation period. This evolution followed a slow pace that reached $1 \mathrm{~cm}$ in the last fortnight of the adaptation period. 
The stems with the number 2, shoots at the beginning of the experimentation, gained about $20 \mathrm{~cm}$ after three weeks. Thereafter, stems accelerated the pace $(50 \mathrm{~cm})$ during the last fortnight and reached more than $1 \mathrm{~m}$ at the end of the adaptation period.

The stems with the number 1, shoots appeared after the 2nd week of the plantation, were quickly reached one meter.

All the identified stems achieved the adaptation period with good health but with a different pace. In fact, the youngest stems were quickly adapted followed by the stems of middle age and the older stems. This could be explained by the resetting of the genetic material of the shoots (modifications in gene expression or in the young embryonic tissue) that allowed a quick adaptation to the new environment $[2,6]$.

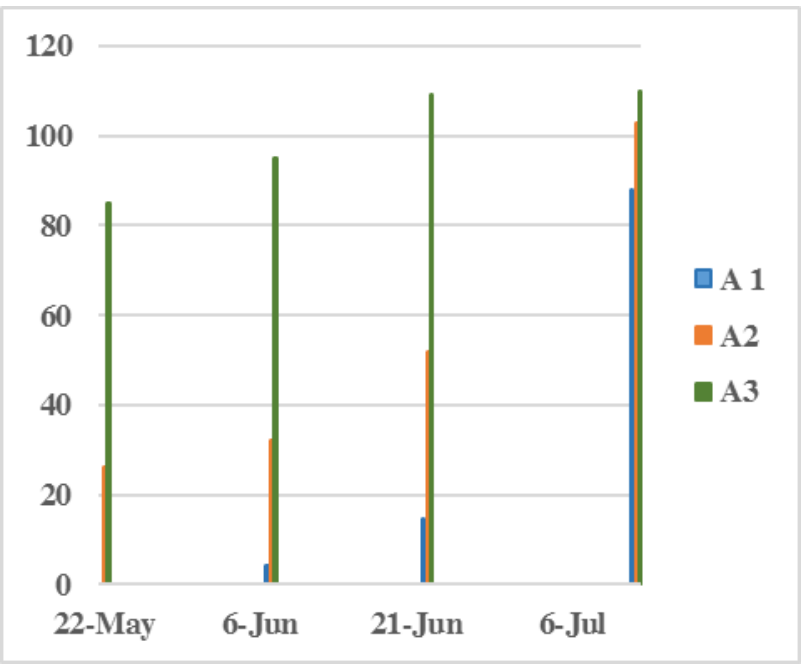

Figure 11: S1- Height evolution of identified stems (cm)

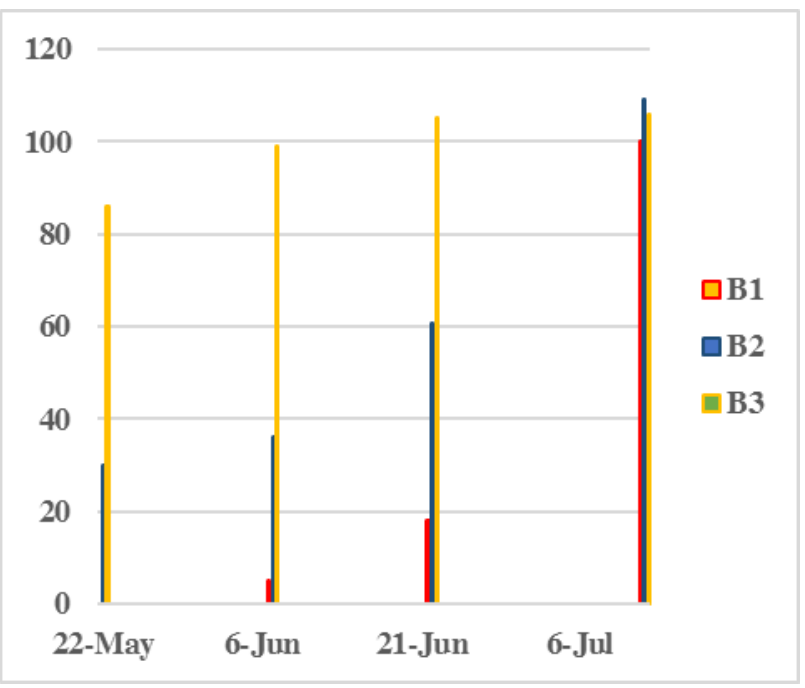

Figure 12:S2- Height evolution of identified stems $(\mathrm{cm})$

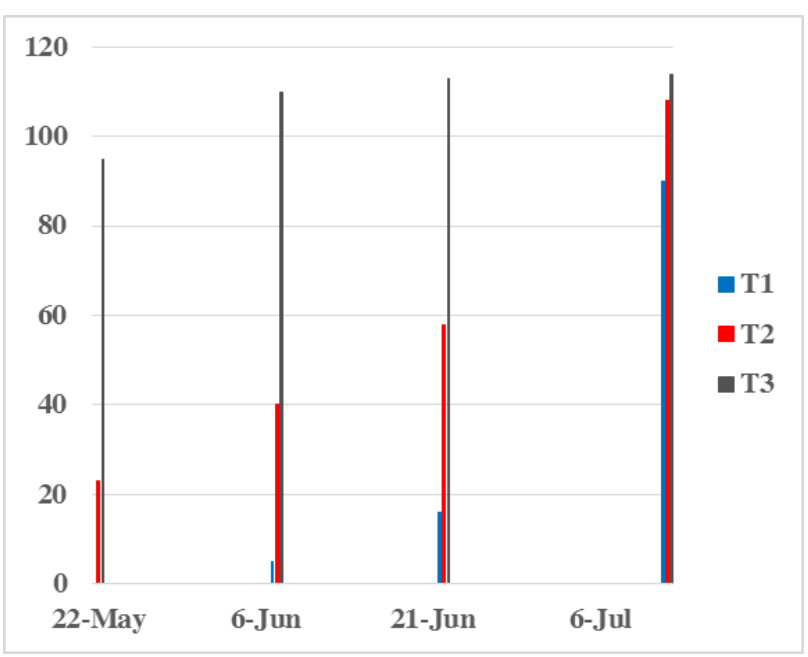

\section{Conclusion}

Except the perturbations observed during the first two weeks, Papyrus Cyperus plants were able to establish mechanisms for adaptation to the conditions of the new environment and have achieved this period in a good health and with a development of organs resembling to the control square.

The ultimate goal of this experiment is to test the purification performance of a CWVF through the use of Papyrus Cyperus as a substitute plant and with filling material available on the local market. The results obtained allowed to start up the filter with its nominal load and to study their performances in order to a possible use for the Moroccan littoral context.

\section{References}

1. C. Grison, Agence de l'Eau Rhône Méditerranée et Corse 11-16 (1999)

2. R. Kadlec, S. Wallace, Taylor \& Francis Group 2 16,87 (2009)

3. Molle P., Sciences Eaux and Territoires 9 24-31 (2012)

4. H. Ruiz, Optimization of French Vertical Flow Treatment Wetlands applied to domestic wastewater treatment for different levels of performances, Doctoral thesis, Ecole nationale supérieure MinesTélécom Atlantique (2017)

5. VYMAZAL, J., \& KROPFELOVA, L. Growth of Phragmites Australis and phalarisa rundinacea in constructed wetlands for wastewater treatment in the Czech republic. Ecological Engineering, 25(5), 606621 (2005)

6. www.ooreka.fr, fiche technique de la plante Papyrus

7. R. Lombard Latune, P. Molle, Quelles plantes pour les filtres plantés de végétaux dans les DOM ?, Irstea, 54 (2015)

8. www.Accuweather.com, données météorologiques de la ville de Rabat (2018) 